\title{
Natural Disasters Preparedness Level of Health Service Centers: A Case Study of Dashti City
}

\author{
Leila Ibrarahimi Ghavamabadi (iD) ${ }^{1, *}$ and Ali Baghbani ${ }^{1}$ \\ ${ }^{1}$ Department of Environmental Management-HSE, Islamic Azad University, Ahvaz Branch, Ahvaz, Iran \\ "Corresponding author: Department of Environmental Management-HSE, Islamic Azad University, Ahvaz Branch, Ahvaz, Iran. Email: ebrahimi.ghavam@gmail.com
}

Received 2019 July 25; Revised 2019 August 28; Accepted 2019 September 14.

\begin{abstract}
Background: The health service centers should have the ability to protect people while facing a natural or man-made disaster and present appropriate performance in disasters.

Objectives: The current study was designed aiming at studying the performance, structural, and non-structural preparedness level of health service centers of Dashti city in Bushehr province.

Methods: This study was performed in 2018. The data collection tool was the standard observational checklist of the world health organization. Sampling was done using a census method to study all health service centers. The data were analyzed with Excel software and descriptive statistics were calculated.

Results: In terms of the performance and preparedness, the investigated health service centers obtained a total score of 39.40, which showed the poor level of preparedness. In terms of structural preparedness, a total score of 77.57 was measured that showed the health service centers were at a good level of structural preparedness. The score of 56.59 for non-structural preparedness revealed a moderate level of non-structural preparedness.

Conclusions: The investigated health service centers in terms of performance were in a poor situation. In terms of the structural dimension, due to improvements accomplished in two recent years, the investigated centers were in a good level of preparedness; but, in terms of the non-structural elements, they were placed in the moderate level. Thus, strategic planning and promotion of health service centers' preparedness are necessary.
\end{abstract}

Keywords: Preparedness, Health Service, Natural Disaster

\section{Background}

Undoubtedly, the unexpected calamities and disasters are considered as complex phenomena that expand quickly in a manner that destruct rapidly and threaten the strategic and real benefits of society (1). These disasters are mostly uncontrollable phenomena that occur all around the world, including our country, Iran $(2,3)$. Disasters may occur suddenly or gradually, accompanying economic damages, human losses, and remarkable psychological disorders. Every year, 200 million humans are involved with these disasters and thousands of individuals lose their lives (4). In the 21st century, earthquakes, flood, volcano, deadly storms, and roaring waves, even in developed countries, still take abundant victims (2). In some parts of the world, these disasters are converted to crisis; but, in some other parts, they remain in the extent of the same incident. The difference in consequences should be searched in the human preparedness for fighting and dealing with disasters. If there is no preparedness, the crisis will appear. Therefore, to have a plan to cope with disasters is a vital issue for any organization (5).

When an incident or crisis occurs, the work conditions are changed completely in the health service centers and enforcement of duties becomes difficult. In fact, the health care centers should be prepared to cope with emergencies which may occur at any time. In such conditions, many deaths and side effects emerge and the demand for sudden therapeutic cares increases (2). The health service centers should be accountable to this increase in demand and they should organize their human and support resources to present the necessary services (6). In a study, the preparedness rate of hospitals of Kermanshah University of Medical Sciences in facing with natural disasters was estimated to be $23.8 \%$, which is a warning for this province, as it is vulnerable to natural disasters (7). The health care centers at the time of calamities should have the ability to protect people, especially patients, in a safe condition (structural and non-structural safety) and also present de- 
sirable performance (8). These centers should gain the necessary knowledge of the management of natural disasters and carry out strategic planning so that at the time of such incidences can act wisely and play their roles appropriately (9). With regard to the experiences of past disasters, the role and importance of performance, structural and nonstructural safety elements have been specified in the uninterrupted serving of health centers. In the meantime, regarding the high costs of non-structural elements, keeping them in a safe condition seems necessary for serving appropriately (10). Dashti city is accounted as one of the catastrophic cities of the country (ruinous flood in 1987 and earthquake of Shonbeh city in 2014).

\section{Objectives}

This study was designed to study the performance, structural, and non-structural preparedness of health service centers of Dashti city.

\section{Methods}

In this study, we used a similar approach to examine all health service centers of Dashti city in Bushehr province, which included 30 health houses, 4 health station, 6 comprehensive health service centers, and one hospital. The data collection tool was the standard observational checklist of the world health organization. This checklist was translated by Ardalan et al. and its reliability and validity were estimated at an acceptable extent. This checklist has been compiled and introduced under the name of safety index. This index has 145 indicators of structural, nonstructural, and safety performance and two preliminary parts including the general information of health care centers and the risks that threaten them (11). Table 1 shows the classification of safety.

The risk cognition dimension is divided into three levels based on its score, as follows:

- Level one: Low-risk level

- Level two: Moderate-risk level

- Level three: High-risk level

The scores of the performance, structural, and nonstructural dimensions were also divided into three levels:

- Level one: Low safety level

- Level two: Moderate safety level

- Level three: High safety level

After completing the checklist, the data were inserted into Excel software and descriptive statistics (central and distributive indices) were calculated. Then, the data analysis was done.

\begin{tabular}{lcc}
\hline Table 1. Classification of Safety & \multicolumn{2}{c}{ Safety Score } \\
\hline \multirow{2}{*}{ Safety Class } & Max & Min \\
\hline \multirow{2yy}{10}{} & 100 & 91 \\
\hline $\mathbf{9}$ & 90 & 81 \\
\hline $\mathbf{8}$ & 80 & 71 \\
\hline $\mathbf{7}$ & 70 & 61 \\
\hline $\mathbf{6}$ & 60 & 51 \\
\hline $\mathbf{5}$ & 50 & 41 \\
\hline $\mathbf{4}$ & 40 & 31 \\
\hline $\mathbf{3}$ & 30 & 21 \\
\hline $\mathbf{2}$ & 20 & 11 \\
\hline $\mathbf{1}$ & 10 & 0 \\
\hline
\end{tabular}

\section{Results}

The performance, structural, and non-structural preparedness scores were measured for the health service centers of Dashti city. In terms of performance preparedness, the investigated centers acquired a total score of 39.40. As Table 2 shows, the preparedness level of the centers was poor. In terms of structural preparedness, the health service centers acquired a total score of 77.57. As Table 3 presents, the preparedness level of the investigated health care was good.

In terms of non-structural preparedness, the health care centers gained a total score of 56.59. As Table 4 shows, the non-structural preparedness level of the investigated

\begin{tabular}{|c|c|}
\hline Unit & Performance Preparedness Score \\
\hline House of health & 39.1 \\
\hline Health station & 39.2 \\
\hline $\begin{array}{l}\text { Comprehensive health service } \\
\text { centers }\end{array}$ & 39.4 \\
\hline Hospital & 39.8 \\
\hline $\begin{array}{l}\text { mean score of performance } \\
\text { preparedness }\end{array}$ & 39.4 \\
\hline
\end{tabular}

Table 3. The Structural Preparedness Level of Health Service Centers

\begin{tabular}{lc}
\hline Unit & Structural Preparedness Score \\
\hline House of health & 73.6 \\
\hline Health station base & 75 \\
\hline Comprehensive health service centers & 71.6 \\
Hospital & 90 \\
\hline Total score of structural preparedness & 77.5 \\
\hline
\end{tabular}




\begin{tabular}{lc}
$\begin{array}{l}\text { Table 4. The Non-Structural Preparedness Level of Investigated Health Service Cen- } \\
\text { ters }\end{array}$ & $\begin{array}{c}\text { Non-Structural Preparedness } \\
\text { Score }\end{array}$ \\
\hline Unit & 58.6 \\
\hline House of health & 55.7 \\
\hline Health station base & 55.0 \\
\hline $\begin{array}{l}\text { Comprehensive health service } \\
\text { centers }\end{array}$ & 56.9 \\
$\begin{array}{l}\text { Hospital } \\
\text { Total score of non-structural } \\
\text { preparedness }\end{array}$ & 56.5 \\
\hline
\end{tabular}

\begin{tabular}{lc}
\hline Table 5. The Overall Preparedness Level of Health Service Centers \\
\hline Unit & Overall Preparedness Score \\
\hline House of health & 57.1 \\
Health station base & 56.6 \\
\hline Comprehensive health service centers & 55.3 \\
Hospital & 62.2 \\
\hline
\end{tabular}

centers was moderate.

The overall preparedness level of the investigated centers in terms of performance, structural and nonstructural preparedness is presented in Table 5.

In terms of risks threatening health care centers of Dashti city, the main risk for the centers was related to the climatic factors, as shown in Figure 1. In terms of overall preparedness, the investigated centers gained a total score of 39.40, which showed a weak situation. In terms of structural preparedness, by acquiring a total score of 77.57, they were in a good situation and by acquiring a score of 56.59, they were placed in a moderate level of non-structural preparedness.

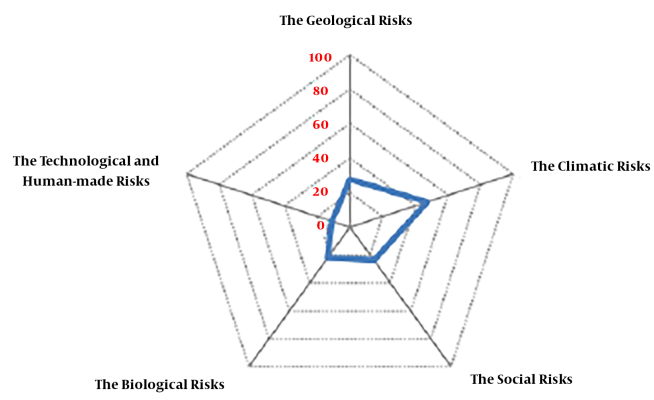

Figure 1. The probability of the occurrence of risks in the investigated centers

\section{Discussion}

In this study, the preparedness level of health houses with a score of 57.12 rated on safety level 5, which indicated a good preparedness situation. The results are supported by Hojat (8). In the current study, the preparedness rate of health station and centers of comprehensive health services with a score of 50 gained safety level 5 , indicating a good preparedness situation. The same results were reported by Hojat (8) and Amiri et al. (12). Also, in the study by Rabeian et al., the most and the least preparedness levels for earthquakes were in the domains of management of unexpected disaster plan and planning for decreasing building dangers, respectively (13). The results of this study showed that the preparedness level of the investigated hospital with a score of 70 gained safety level 8 , which showed its good preparedness situation. The results of another study by Amiri et al. showed that two hospitals under study had moderate and low preparedness levels when facing unexpected disasters (12). Barfield et al. reported the vital role of health service personnel's preparedness in enhancing the quality of health services during the occurrence of natural disasters (14). Hamele et al. stated the need for strategic planning to improve accountability and preparedness of health care services prior to natural disasters (15). Generally, in the domain of structural elements safety, the studied centers had moderate to high preparedness levels that contradicted the results of other studies (4, 16). Although these elements may not have direct effects on the performance of centers, their destruction at the time of natural disasters such as earthquakes can have serious adverse impacts on the efficiency of different parts. The cause of low preparedness in most studies is the lack of sufficient supervision by the related authorities during the construction of health care centers.

\subsection{Conclusions}

The results of the current study showed that the investigated centers in terms of preparedness were in a poor situation. In terms of structural dimension, due to improvements in two recent years, the investigated centers were in a good preparedness situation; but, in terms of nonstructural safety elements, they were placed in a moderate level. Concerning our results, strategic planning and promoting the safety and quality of services are crucial. With regard to the high costs of building repairs, settlement of facilities, equipment, and infrastructural development, it is suggested that, along with developing the appropriate plans for management of disasters, the non-structural and performance of centers be considered as a priority. 


\section{Acknowledgments}

The authors would like to give thier thanks to the corresponding authorities of local health care centers of Dashti city.

\section{Footnotes}

Authors' Contribution: The first author revised the manuscript, designed and conceptualized the study; the second author collected the data and drafted the manuscript.

Conflict of Interests: The authors declare no conflicts of interest.

Ethical Approval: Researchers received introductory letters from the Islamic Azad University, Ahvaz Branch (Ethical code: IR.iaua.ac.ir,952004).

Funding/Support: Islamic Azad University, Ahvaz Branch funded the study (research code: 10650508952004).

\section{References}

1. Pearson CM, Sommer SA. Infusing creativity into crisis management: An essential approach today. Organ Dyn. 2011;40(1):27-33. doi: 10.1016/j.orgdyn.2010.10.008.

2. Asefzadeh S, Rajaee R, Ghamari F, Kalhor R, Gholami S. Preparedness of Iranian hospitals against disasters. Biotech Health Sci.2016;3(3). doi: 10.17795/bhs-35073.

3. Charney RL, Rebmann T, Esguerra CR, Lai CW, Dalawari P. Public perceptions of hospital responsibilities to those presenting without medical injury or illness during a disaster. J Emerg Med. 2013;45(4):578-84. doi: 10.1016/j.jemermed.2013.05.010. [PubMed: 23845529].

4. Djalali A, Castren M, Hosseinijenab V, Khatib M, Ohlen G, Kurland L. Hospital Incident Command System (HICS) performance in Iran; decision making during disasters. Scand J Trauma Resusc Emerg Med. 2012;20:14. doi: 10.1186/1757-7241-20-14. [PubMed: 22309772]. [PubMed Central: PMC3296571].

5. Royal S, Smeaton L, Avery AJ, Hurwitz B, Sheikh A. Interventions in primary care to reduce medication related adverse events and hospital admissions: Systematic review and meta-analysis. Qual Saf
Health Care. 2006;15(1):23-31. doi: 10.1136/qshc.2004.012153. [PubMed: 16456206]. [PubMed Central: PMC2563996].

6. Zaboli R, Sh T, Amerion A, Moghaddasi H. Survey of Tehran city hospitals disaster preparedness for disaster.J Mil Med. 2006;8(2):103-11.

7. Djalali A, Castren M, Khankeh H, Gryth D, Radestad M, Ohlen G, et al. Hospital disaster preparedness as measured by functional capacity: A comparison between Iran and Sweden. Prehosp Disaster Med. 2013;28(5):454-61. doi: 10.1017/S1049023X13008807. [PubMed: 23962358].

8. Hojat M. Disaster preparedness in hospitals of Jahrom University of Medical Sciences (2010). J Qazvin Univ Med Sci. 2012;16(3):72-7.

9. Paganini M, Borrelli F, Cattani J, Ragazzoni L, Djalali A, Carenzo L, et al. Assessment of disaster preparedness among emergency departments in Italian hospitals: A cautious warning for disaster risk reduction and management capacity. Scand J Trauma Resusc Emerg Med. 2016;24(1):101. doi: 10.1186/s13049-016-0292-6. [PubMed: 27526719]. [PubMed Central: PMC4986169].

10. Kearns RD, Conlon KM, Valenta AL, Lord GC, Cairns CB, Holmes JH, et al. Disaster planning: The basics of creating a burn mass casualty disaster plan for a burn center. J Burn Care Res. 2014;35(1):e1-e13. doi: 10.1097/BCR.ob013e31829afe25. [PubMed: 23877135].

11. Yarmohammadian MH, Atighechian G, Shams L, Haghshenas A. Are hospitals ready to response to disasters? Challenges, opportunities and strategies of Hospital Emergency Incident Command System (HEICS). J Res Med Scie. 2011;16(8):1070-7. [PubMed: 22279484]. [PubMed Central: PMC3263085].

12. Amiri M, Chaman R, Raei M, Nasrollahpour Shirvani SD, Afkar A. Preparedness of hospitals in north of Iran to deal with disasters. Iran Red Crescent Med J. 2013;15(6):519-21. doi: 10.5812/ircmj.4279. [PubMed: 24349752]. [PubMed Central: PMC3840841].

13. Rabeian M, Hosseini SH, Radabadi M, Taheri Mirghaed M, Bakhtiari M Evaluation of effective factors on the rate of preparedness of Tehran University of Medical Sciences' selected hospitals in dealing with earthquake.J Payavard Salamat. 2013;7(3):251-61.

14. Barfield WD, Krug SE; Committee on Fetus and Newborn; Disaster Preparedness Advisory Council. Disaster preparedness in neonatal intensive care units. Pediatrics. 2017;139(5). doi: 10.1542/peds.2017-0507. [PubMed: 28557770].

15. Hamele M, Neumayer K, Sweney J, Poss WB. Always ready, always prepared-preparing for the next pandemic. Transl Pediatr 2018;7(4):344-55. doi: 10.21037/tp.2018.09.06. [PubMed: 30460186]. [PubMed Central: PMC6212382].

16. Gomez D, Haas B, Ahmed N, Tien H, Nathens A. Disaster preparedness of Canadian trauma centres: The perspective of medical directors of trauma. Can J Surg. 2011;54(1):9-16. doi: 10.1503/cjs.022909. [PubMed: 21251427]. [PubMed Central: PMC3038366]. 